\title{
Indicators for Assessing Social Sustainability of Bioenergy Systems: A Literature Review and Future Research Agenda
}

\author{
Sirikumara K.J.* \\ Sri Lanka Standards Institution, Colombo 08, Sri Lanka \\ *jayantha@slsi.lk
}

\begin{abstract}
There are pressing reasons for developing a better understanding group of indicators to assess social, economic and environmental sustainability of bioenergy systems. Therefore an important current research need is to develop a group of indicators for acceptable social sustainability. Effective indicators can help to identify and quantify the sustainability attributes of bioenergy options. Therefore, the aim of this paper is to critically review the indicators that assess the social sustainability of bioenergy systems. A comprehensive literature review and a desk study of 20 key research papers written on bioenergy are analysed in this research study. This research identified a selection of indicators influencing sustainability criteria for bioenergy under social sustainability. 16 social indicators are identified from the literature review for social well-being, labour rights, water use right, land use right and land use change, social acceptability, resource conservation and energy security. 16 indicators identified under seven categories from literature review will be used to identify critical indicators affecting the sustainability criteria for bioenergy during the next phase of the study. These critical indicators are hypothesized to be practical toolset for capturing key social effects of bioenergy across a range of bioenergy system, including different pathways, locations, and management practices. To evaluate the hypothesis that the toolset meet this goal, and also to help measure variability and establish appropriate targets, the toolset should be field tested in systems spanning a wide variety of conditions. If the hypothesis is confirmed, the toolset can be implemented more broadly, modified as necessary for particular situation.
\end{abstract}

Keywords: Bioenergy sustainability, Social indicators, Food security, Biodiversity 